ARTIFICIAL SATELLITES, Vol. 48, No. 3 - 2013
DOI: 10.2478/arsa-2013-0008

\title{
EGNOS LIMITATIONS OVER CENTRAL AND EASTERN POLAND - RESULTS OF PRELIMINARY TESTS OF EGNOS-EUPOS INTEGRATION PROJECT
}

Leszek Jaworski, Anna Swiatek, Ryszard Zdunek

Space Research Centre Polish Academy of Sciences

\begin{abstract}
The problem of insufficient accuracy of EGNOS correction for the territory of Poland, located at the edge of EGNOS range is well known. The EEI PECS project (EGNOS EUPOS Integration) assumes improving the EGNOS correction by using the GPS observations from Polish ASG-EUPOS stations.

One of the EEI project tasks was the identification of EGNOS performance limitations over Poland and services for EGNOSS-EUPOS combination. The two sets of data were used for those goals:

statistical, theoretical data obtained using the SBAS simulator software, real data obtained during the measurements.

The real measurements were managed as two types of measurements: static and dynamic. Static measurements are continuously managing using Septentrio PolaRx 2 receiver. The SRC permanent station works in IMAGE/PERFECT project. Dynamic measurements were managed using the Mobile GPS Laboratory (MGL). Receivers (geodetic and navigation) were working in two modes:

determining navigation position from standalone GPS, determining navigation position from GPS plus EGNOS correction.

The paper presents results of measurements' analyses and conclusions based on which the next tasks in EEI project are completed.

Keywords: GPS, GNSS, EGNOS

\section{INTRODUCTION}

EGNOS - the European Geostationary Navigation Overlay Service is the Space Base Augmentation System (SBAS). EGNOS delivers the signal containing the corrections for GNSS observations. Such information increases reliability and accuracy of the satellite positioning. The EGNOS corrections are computed using the GNSS observations, delivered by 34 Ranging and Integrity Monitoring Stations (RIMS) and transmitted to the users by three geostationary satellites. Full system description is available in (EGNOS - A Cornerstone of Galileo, 2006) or at the WebPages of ESA: http://www.esa.int/esaNA/egnos.html. Since 1 October 2009 the EGNOS Open Service has been available and since 02 March 2011 the Safety of Life service has been officially available for aviation (Safety of Life Service Definition Document, 2011). Unfortunately the accuracy and availability of corrections in the
\end{abstract}


eastern part of Europe are degraded because of RIMS stations location. EUPOS (European Position Determination System) is a ground based European regional GNSS augmentation system created for Central and Eastern Europe (EUPOS Technical Standards, 2008). The main purpose of EUPOS project is to define the national geodetic reference system in these countries. The EUPOS is based on hundreds of reference stations deployed in Germany, Poland, Czech Republic and other countries of the Central Europe. In Poland only the network consists of more than 80 stations (Bosy et. al. 2007). High density of the stations is required for precise real time geodetic application. The main purposes of this task of the project were an analysis of shortcomings of EGNOS in Poland.

\section{TESTS OF ACCURACY OF EGNOS IN POLAND}

The EGNOS-EUPOS Integration project assumes an improvement of determining position by use of new correction computed using GNSS data from Polish EUPOS stations (Jaworski and Swiatek, 2009). All models of ionosphere applied for maps or corrections are of some mathematical and physical approximation of real conditions. Some assumptions made during their preparation can generate specific inaccuracies in relation to real values. Those differences between models and real conditions are more visible during the time of disturbance. For more complete review we should analyse the ionosphere for quiet time as well as for disturbed time. The 11-year solar activity cycle had its maximum in 2000-2002 and minimum in 2007-2009. Because of the EGNOS works since 2006 (the archived correction are available on EMS) the corrections computed during that period refer to quite quiet period of geomagnetic activity. The nearest solar cycle maximum is predicted for 2013 . At the beginning of the project realisation the test measurements were made. They consist of two types - static and dynamic.

\section{STATIC TESTS}

For the static tests the data from Septentrio PolaRx2 receiver working at Warsaw SRC building was used. That permanent station works for ESA Real Time Performance project. Although there are other services available, which collect the data from the whole Europe about accuracy, integrity, availability and continuity of EGNOS signal, such as EDCN, access to the data is restricted to registered users (Antemijczuk et. al. 2011). The results of measurement made for selected quiet and disturbed days are presented for comparison. As a quiet day 13.05.2010 with the $\mathrm{Ap}=3$ was selected, while as a disturbed 15.12.2006 (Ap=94) was selected. The choice of a disturbed day was made for files stored in EMS (EGNOS Message Server) where archival corrections of EGNOS are available. The figures 1-4 present the HPL and VPL values obtained from station SRC (point with coordinates $52.22^{\circ} \mathrm{N}$ and $21.07^{\circ} \mathrm{E}$ ) for quiet and disturbed day respectively.

The computed values of HPL and VPL for selected quiet day exceed 30 meters and they are determined with error less than 3 meters.

The real HPL values for selected disturbed day exceeded 40m, and for VPL they exceeded even $50 \mathrm{~m}$. It is remarkable that those values are greater than for a quiet day.

Unfortunately as it was noticed at the beginning, all cases available to analysis derive from the period of the solar minimum. We could only imagine what might happen in the case of strongly disturbed time (as in years 2003 and 2004). 


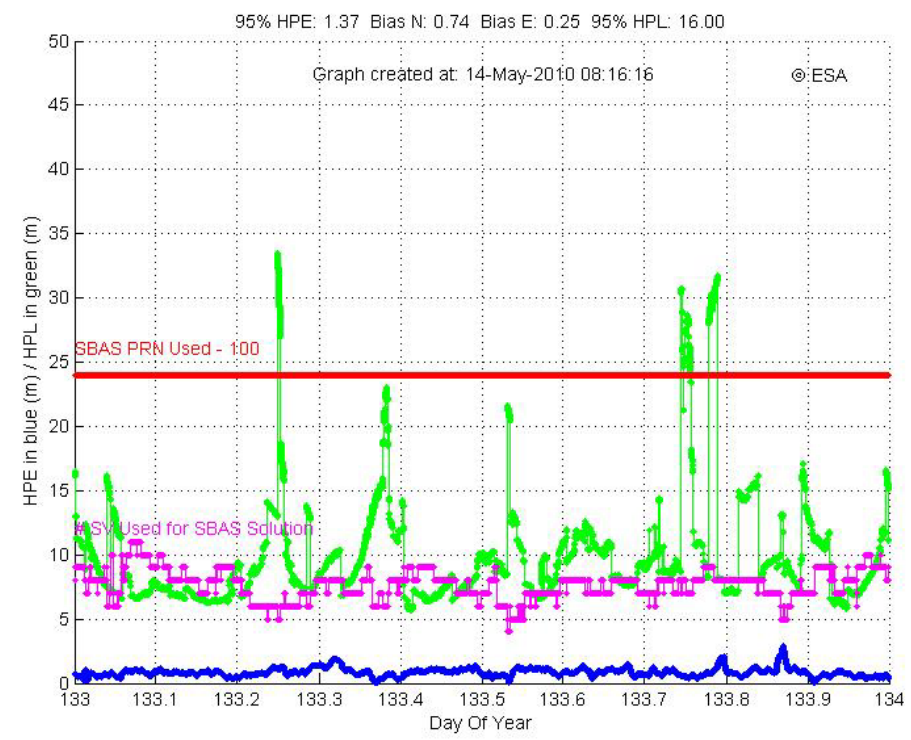

Fig. 1. HPL obtained for 13.05.2010 (quiet day) for ESA Real Time Performance project, formerly ESA IMAGE/PERFECT project station in Warsaw.

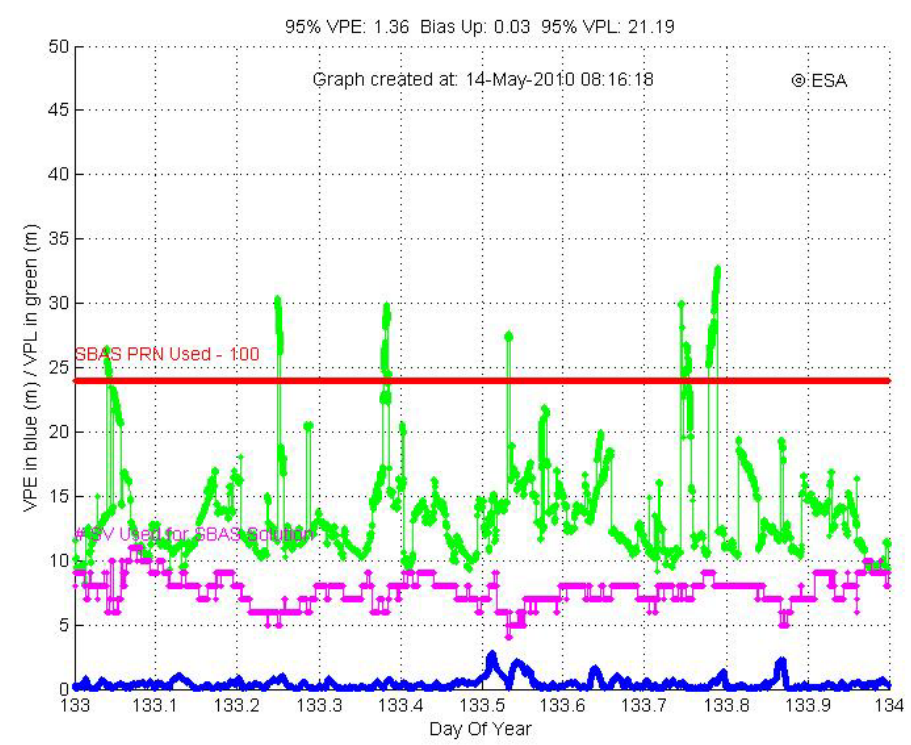

Fig. 2. VPL obtained for 13.05.2010 (quiet day) for ESA Real Time Performance project, formerly ESA IMAGE/PERFECT project station in Warsaw. 


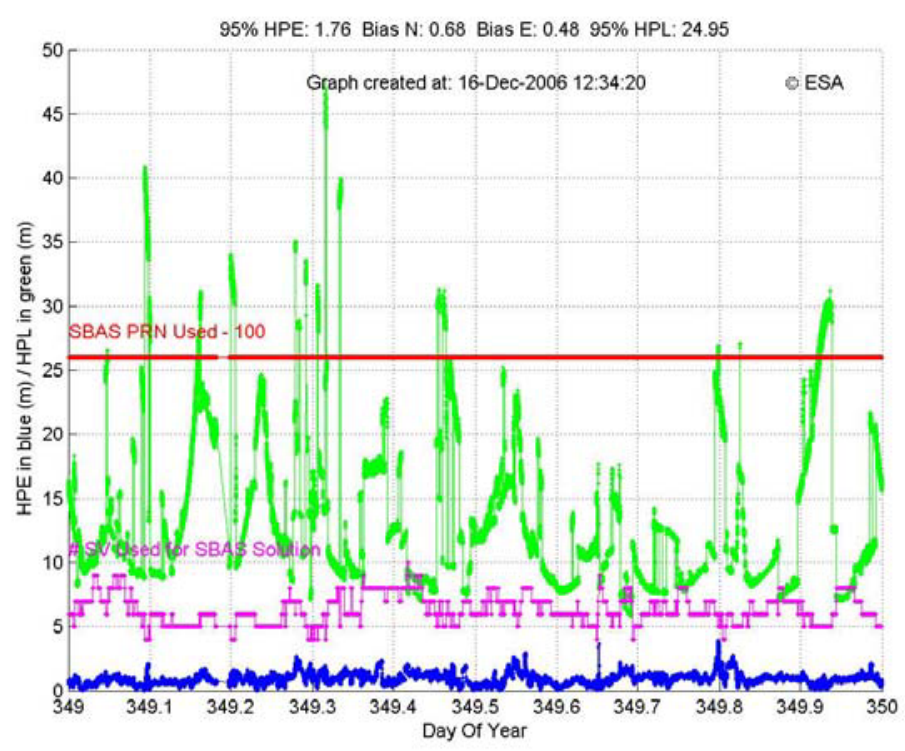

Fig. 3. HPL obtained for 15.12.2006 (disturbed day) for ESA Real Time Performance project, formerly ESA IMAGE/PERFECT project station in Warsaw.

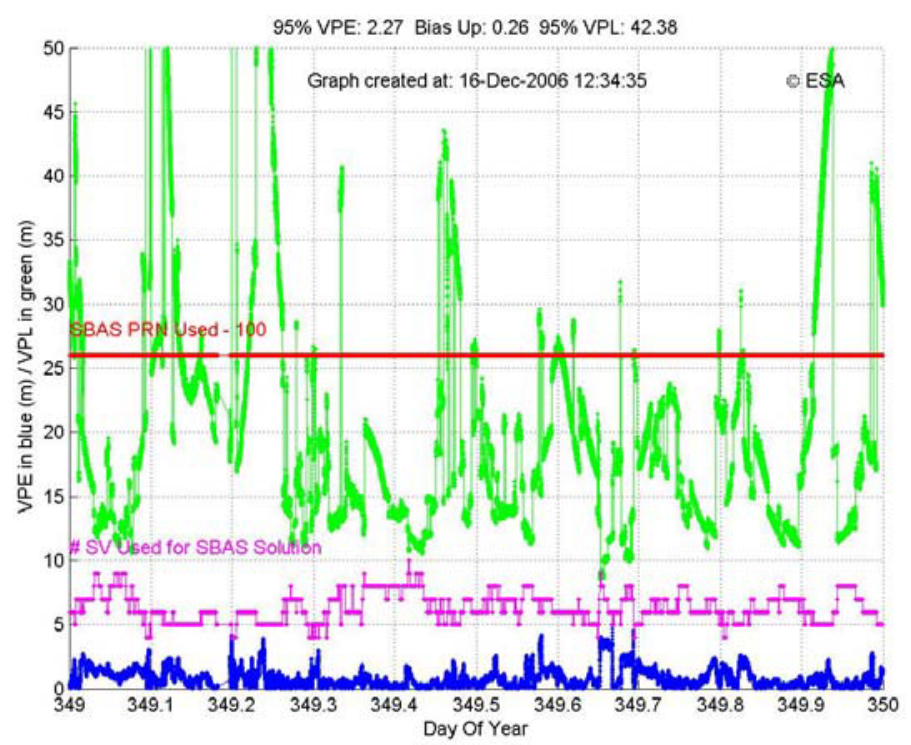

Fig. 4. VPL obtained for 15.12.2006 (disturbed day) for ESA Real Time Performance project, formerly ESA IMAGE/PERFECT project station in Warsaw.

\section{DYNAMIC TESTS}

The dynamic test was made 13.05.2010 for quiet geomagnetic conditions. The car-Mobile GNSS Laboratory was equipped with the set of geodetic and navigation GNSS receivers:

Trimble SPS850 (geodetic dual frequency GPS+GLONASS+EGNOS receiver) with Zephyr Geodetic 2 antenna,

Trimble 5700 (geodetic dual frequency GPS+EGNOS receiver) with Zephyr Geodetic antenna,

Septentrio PolaRX2 (geodetic dual frequency GPS+EGNOS receiver) with AT2775-54SW antenna,

2 receivers Garmin GPS18 (navigation single frequency GPS+EGNOS) - integrated receiverantenna.

All antennas were mounted on the car's roof (see Figure 5). 


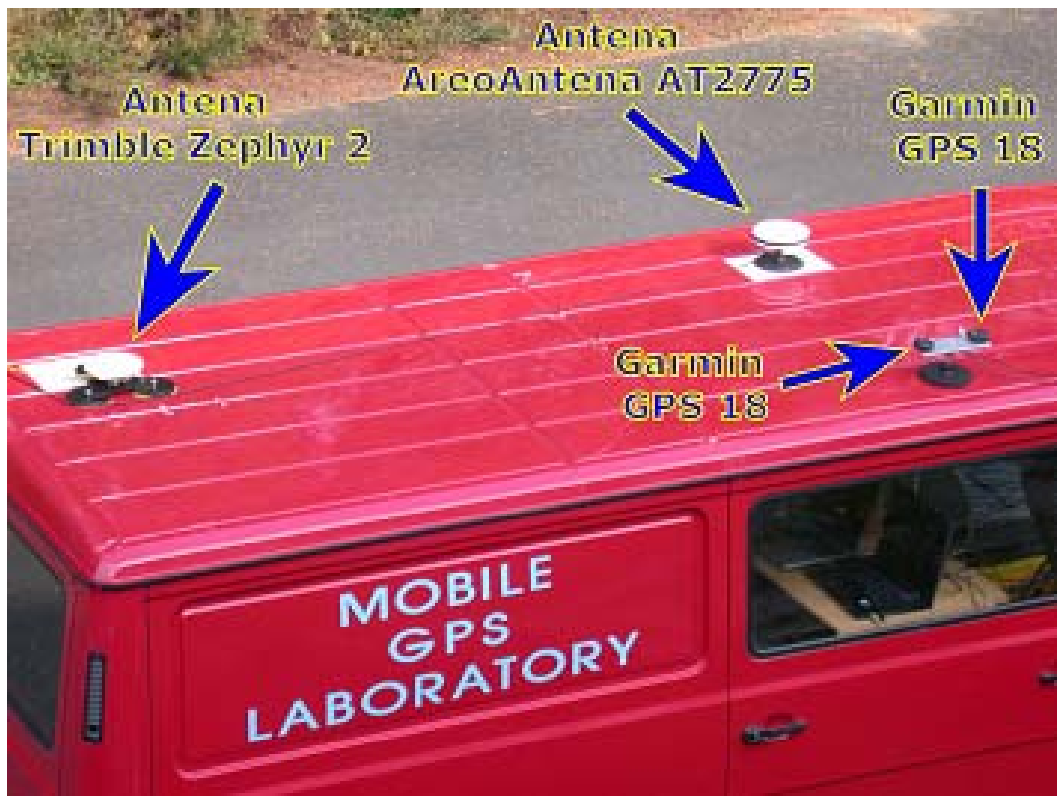

Fig. 5. Location of the antennas on the roof the MGL

The Trimble geodetic receivers measured in stand-alone mode and the data obtained this way was used for kinematic computation of geodetic position of points located along the way of driving car. Those coordinates were the reference points for comparison of navigation position.

The navigation receivers Garmin worked parallel in modes: with and without EGNOS corrections.

In total for the purpose of the test the car passed more than $200 \mathrm{~km}$ and the route was located east of Warsaw. Unfortunately there are no highways in Eastern Poland. The territory of Eastern Poland is forested. Most of the roads are narrow and with trees nearby. Because of the forests and lines of trees situated near the roads, not all saved data could be processed. Only data saved for short sections of travelled route was useful for computations. As an example the results obtained for two selected sections are presented below. Presented results show the coordinates $\mathrm{X}, \mathrm{Y}$ and $\mathrm{H}$ (ellipsoidal height), computed as differences between real values (obtained by kinematic processing of data from geodetic receiver) and navigation data obtained from Garmin receivers.

Presented in Figure $6-\mathrm{a}, \mathrm{b}$ and $\mathrm{c}$ respectively for $\mathrm{X}, \mathrm{Y}$ and $\mathrm{H}$ coordinates results show that EGNOS corrections improved the position.

For both cases were computed the standard deviation for each component which are presented in table 1. The results show that the EGNOS corrections improved X and Y coordinates slightly, and $\mathrm{H}$ significantly. However, the differences from the references values are still big. 


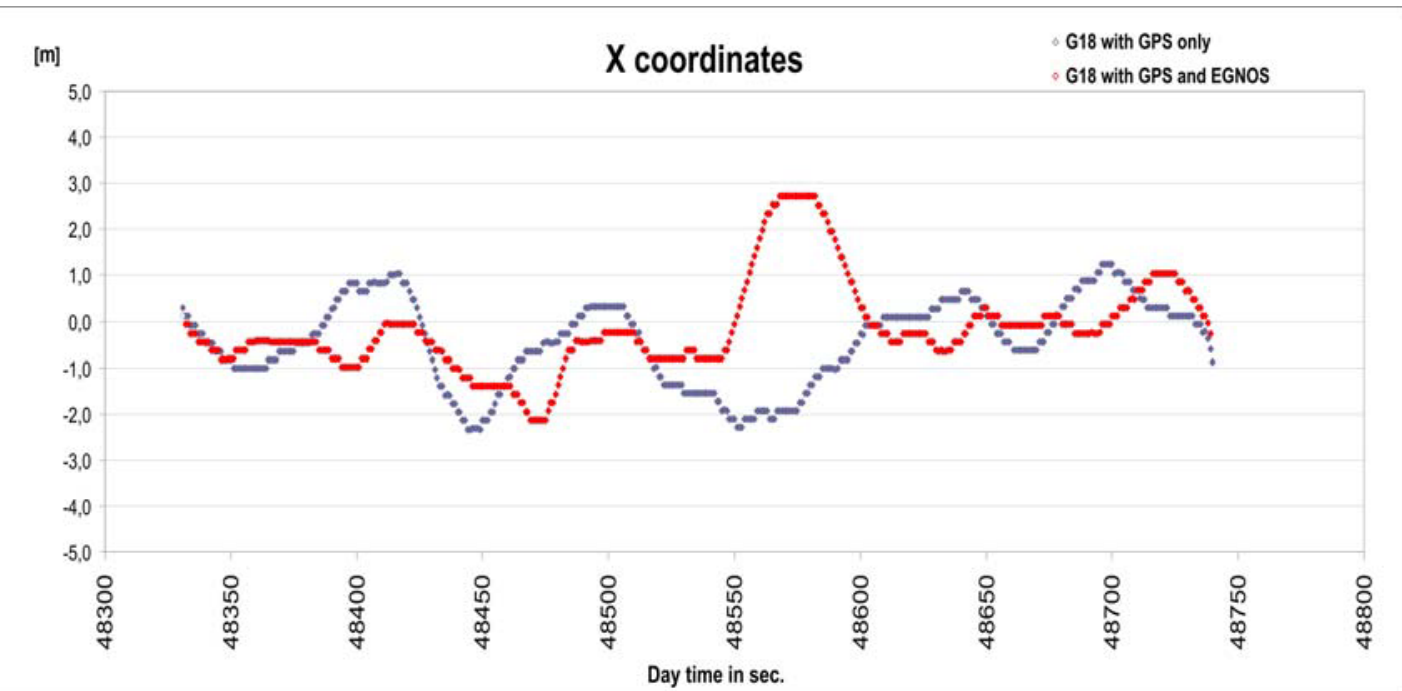

Fig. 6a. The differences of $X$ coordinates computed for Garmin receiver with and without EGNOS

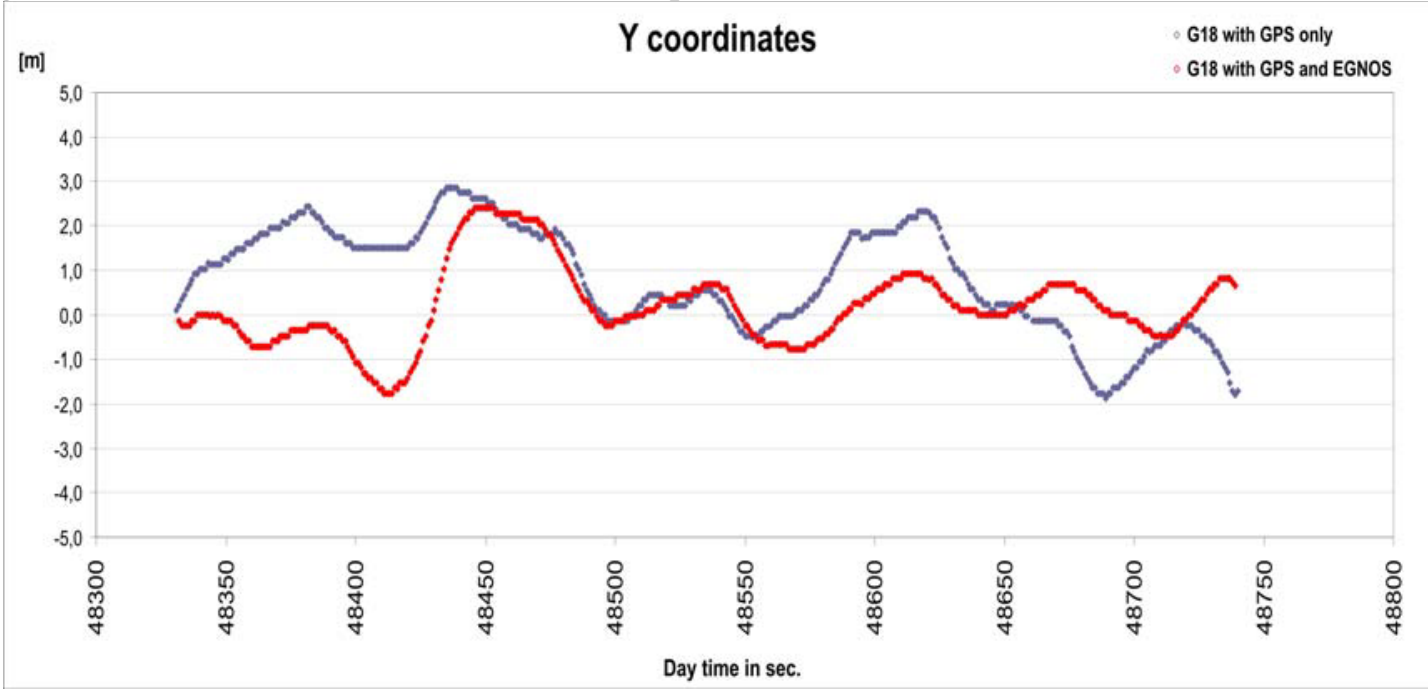

Fig. 6b. The differences of Y coordinates computed for Garmin receiver with and without EGNOS

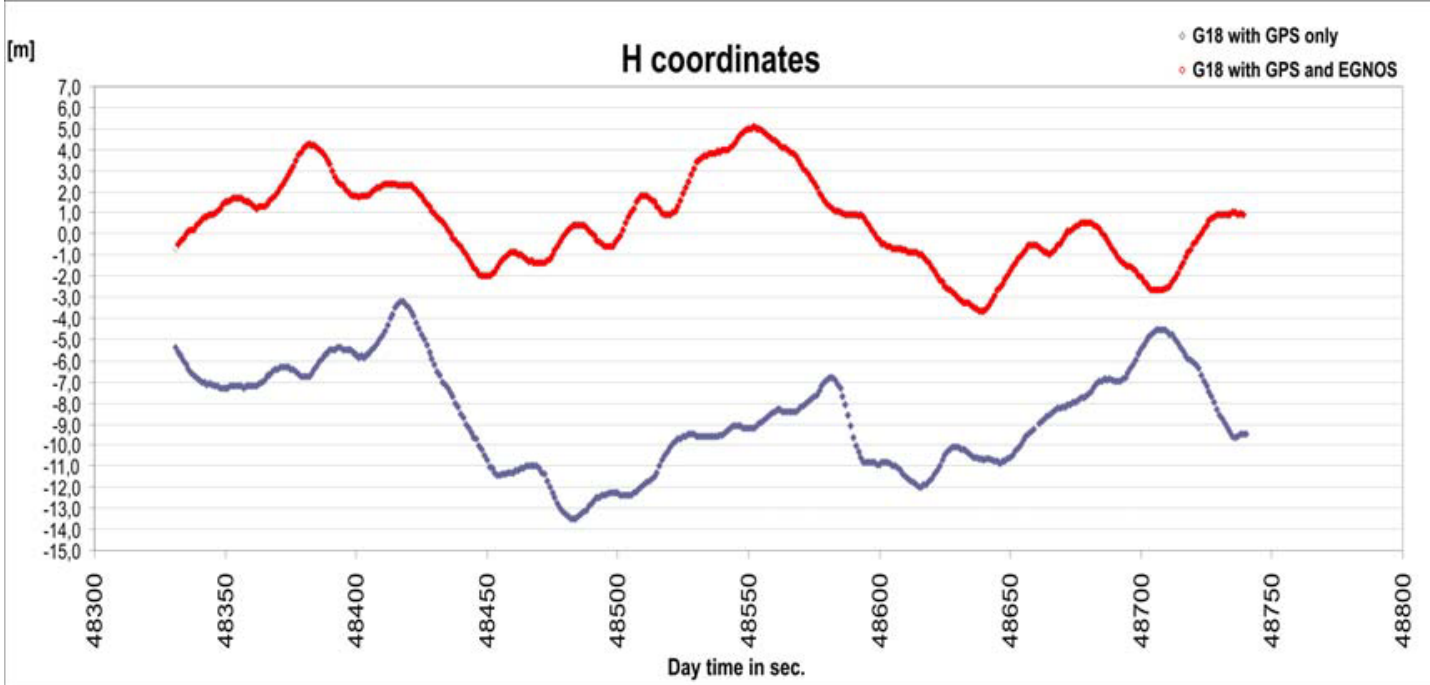

Fig. 6c. The differences of $\mathrm{H}$ coordinates computed for Garmin receiver with and without EGNOS 
Table 1. Standard deviation computed for $\mathrm{dX}, \mathrm{dY}$ and $\mathrm{dH}$ for results of data computation for Garmin G18 receivers

\begin{tabular}{|c|c|c|c|}
\hline Configuration & $\mathrm{dX}$ & $\mathrm{dY}$ & $\mathrm{dH}$ \\
\hline Without EGNOS & 0.920 & 1.183 & 2.445 \\
\hline With EGNOS & 0.992 & 0.881 & 2.061 \\
\hline
\end{tabular}

For the same period results obtained for Septentrio receiver with EGNOS corrections show better compliance with reference position (see Figures $7-\mathrm{a}, \mathrm{b}$ and $\mathrm{c}$ for $\mathrm{X}, \mathrm{Y}$ and $\mathrm{H}$ components respectively). The standard deviations computed for each component are presented in Table 2.

Table 2. Standard deviation computed for $\mathrm{dX}, \mathrm{dY}$ and $\mathrm{dH}$ component for results of data computation for Septentrio receiver

\begin{tabular}{|c|c|c|c|}
\hline Configuration & $\mathrm{dX}$ & $\mathrm{dY}$ & $\mathrm{dH}$ \\
\hline With EGNOS & 0.273 & 0.600 & 0.798 \\
\hline
\end{tabular}

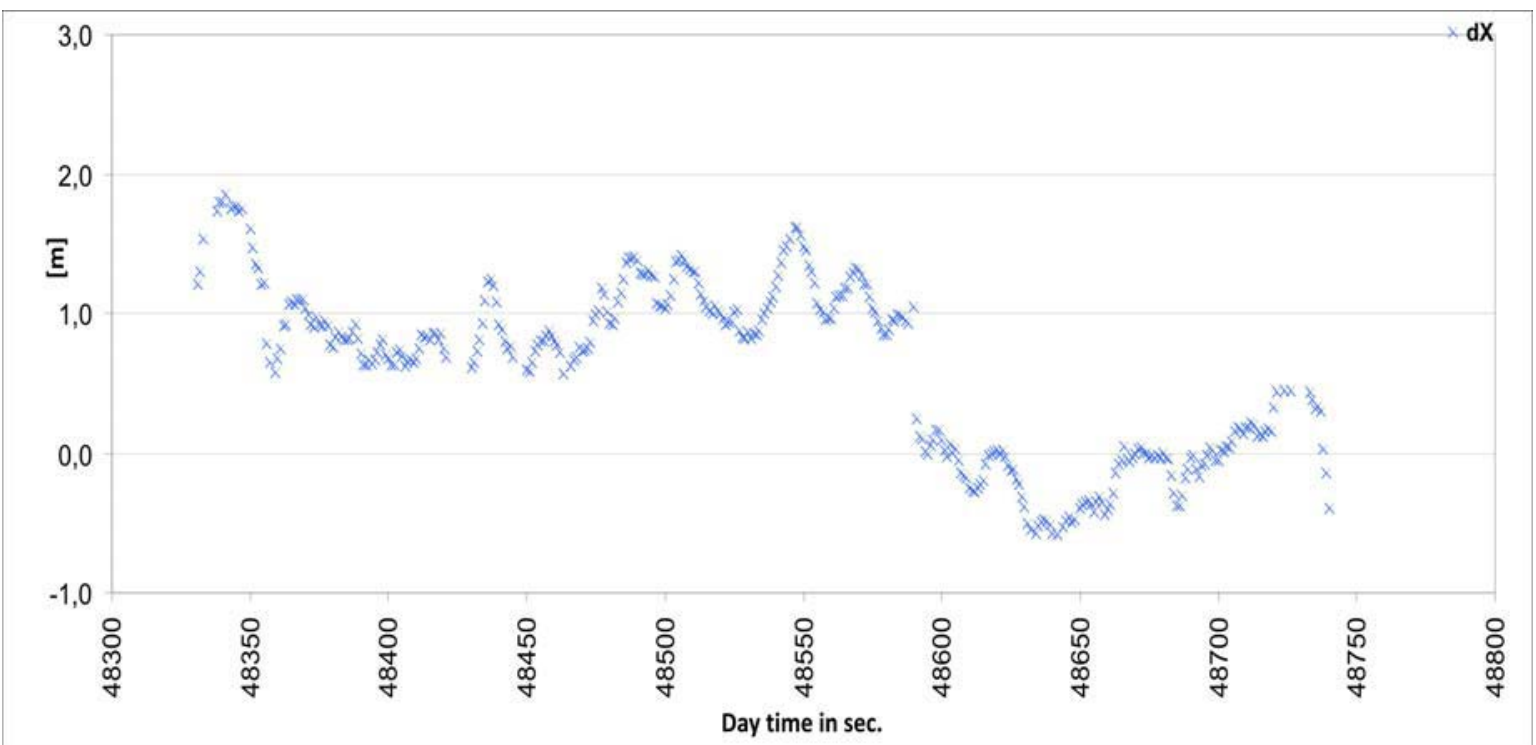

Fig. 7a. The differences of $X$ coordinates computed for Septentrio receiver with EGNOS 


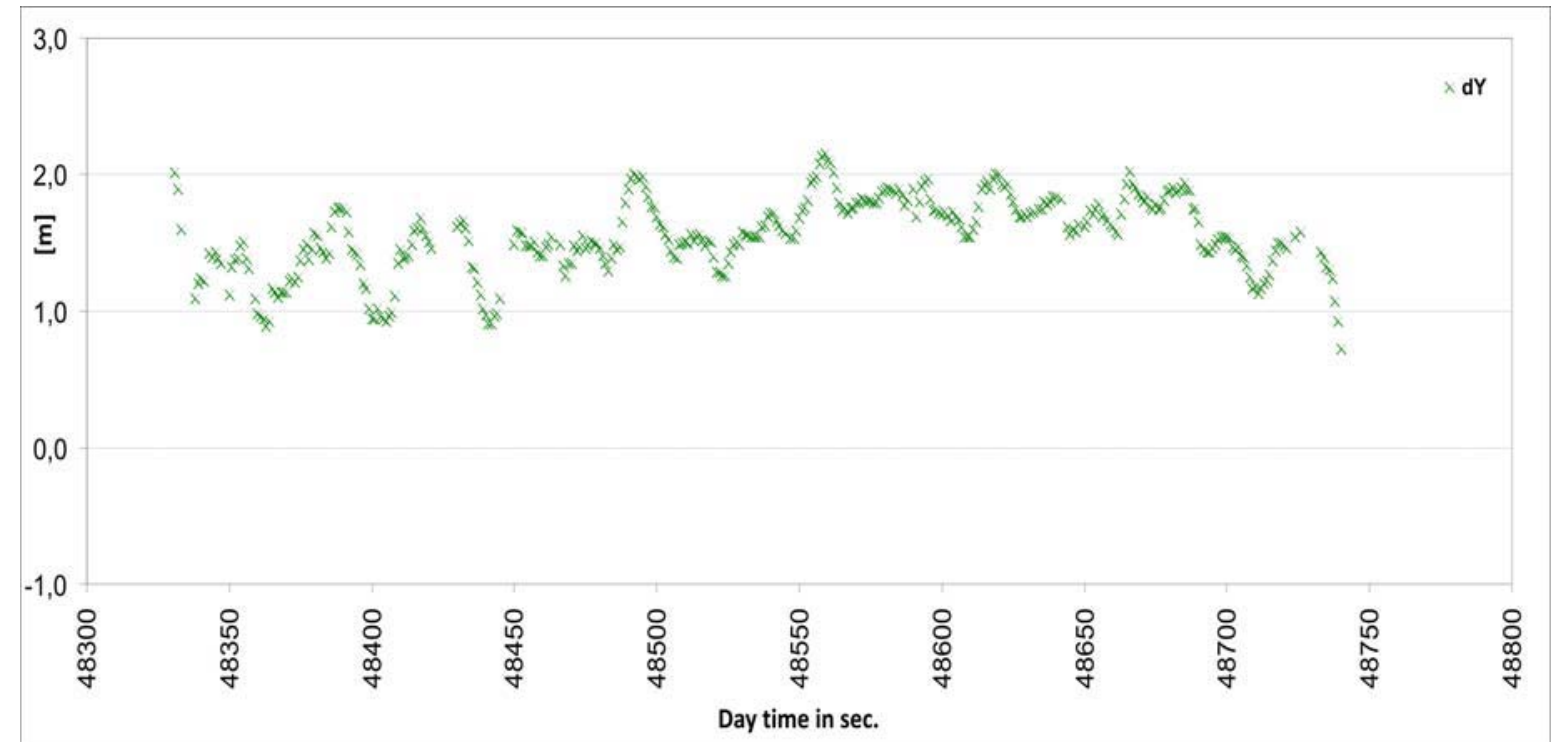

Fig. 7b. The differences of $Y$ coordinates computed for Septentrio receiver with EGNOS

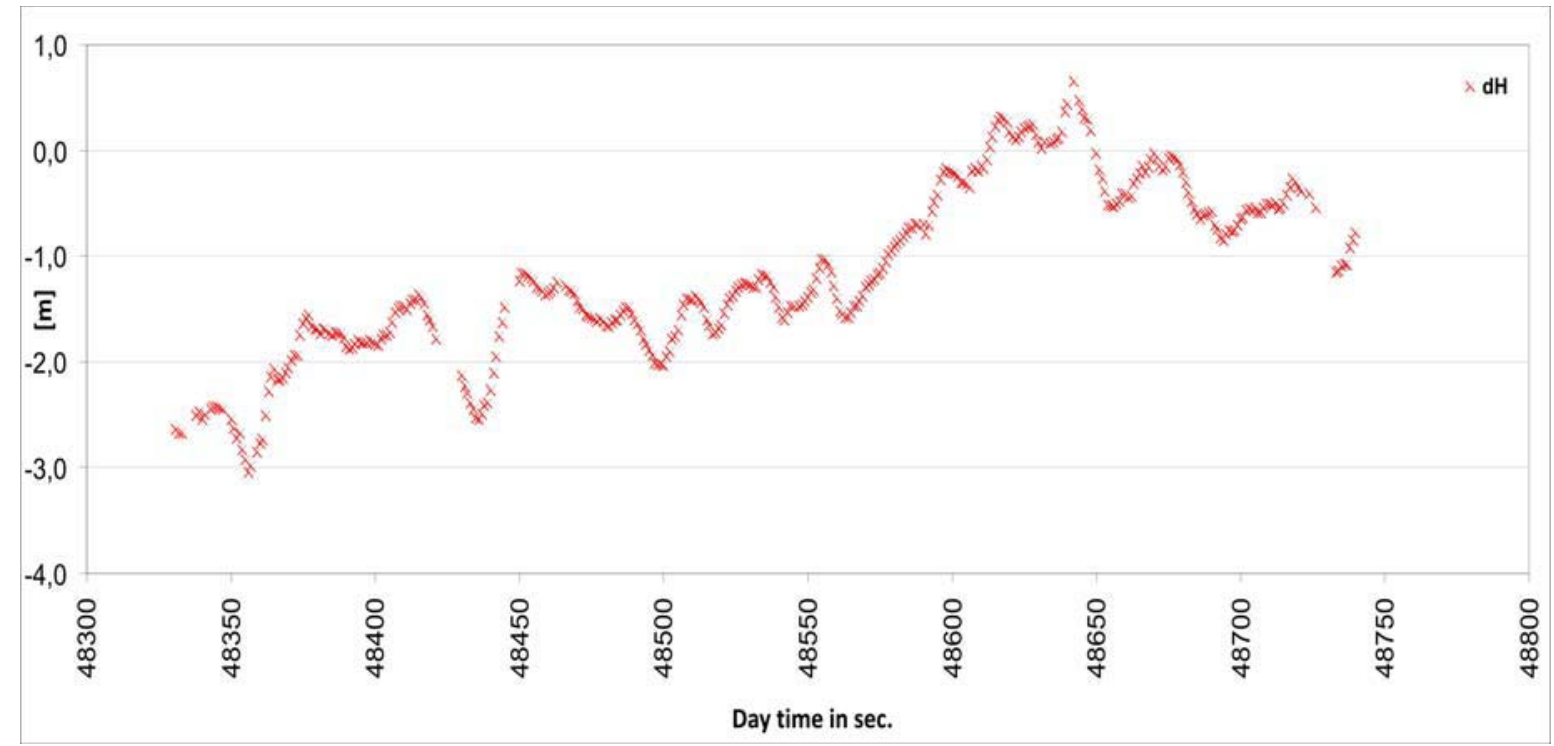

Fig. 7c. The differences of $\mathrm{H}$ coordinates computed for Septentrio receiver with EGNOS

Another time period presented for Septentrio receiver shows worse results. This may be caused by higher speed of car-laboratory and different environmental conditions (more trees in vicinity of the road) The Figure $8-\mathrm{a}, \mathrm{b}$ and $\mathrm{c}$ presents the $\mathrm{X}, \mathrm{Y}$ and $\mathrm{H}$ coordinates respectively and Table 3 the standard deviations computed for $\mathrm{dX}, \mathrm{dY}$ and $\mathrm{dH}$ components.

Table 3. Standard deviation computed for $\mathrm{dX}, \mathrm{dY}$ and $\mathrm{dH}$ component for results of data computation

for Septentrio receiver

\begin{tabular}{|c|c|c|c|}
\hline Configuration & $\mathrm{dX}$ & $\mathrm{dY}$ & $\mathrm{dH}$ \\
\hline With EGNOS & 0.669 & 0.837 & 1.124 \\
\hline
\end{tabular}




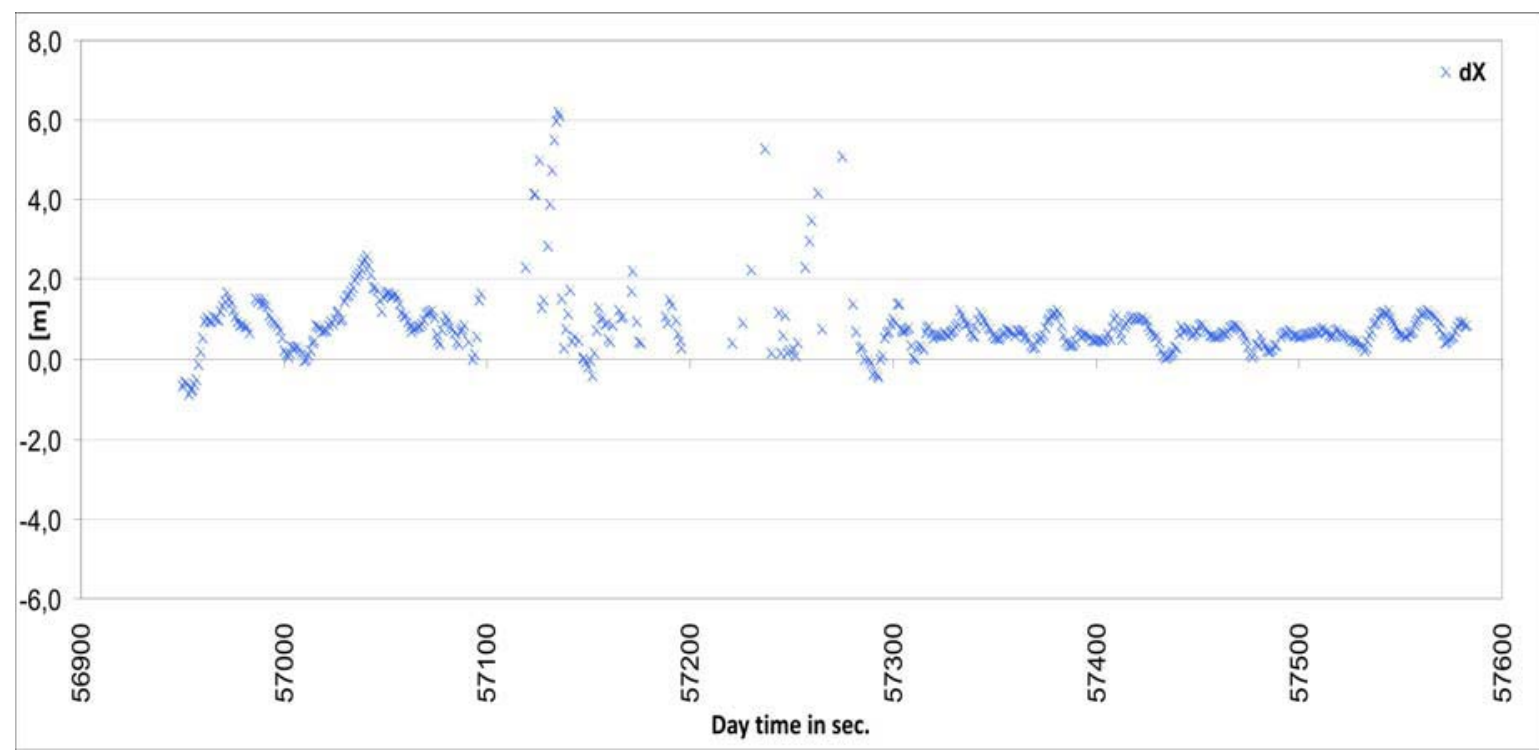

Fig. 8a. The differences of $X$ coordinates computed for Septentrio receiver with EGNOS

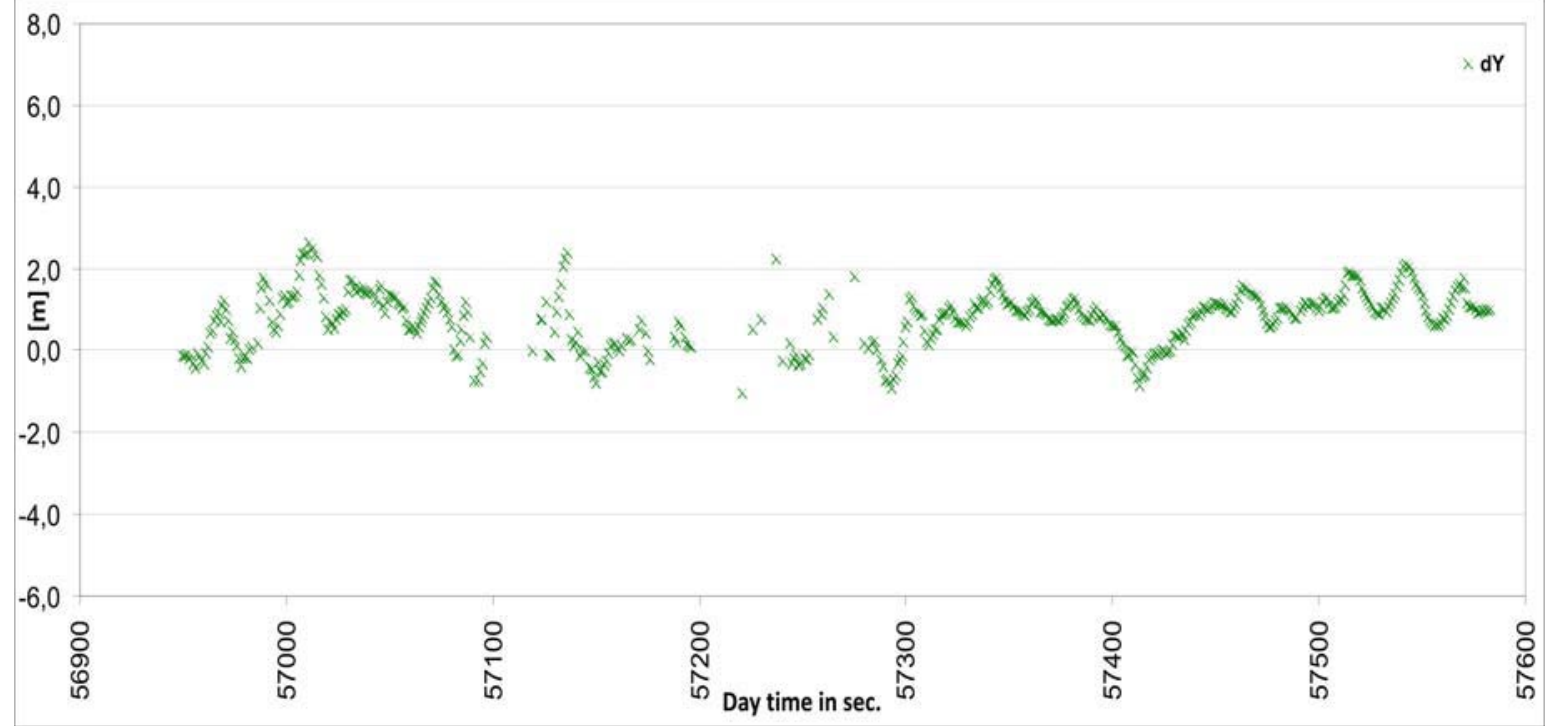

Fig. 8b. The differences of Y coordinates computed for Septentrio receiver with EGNOS

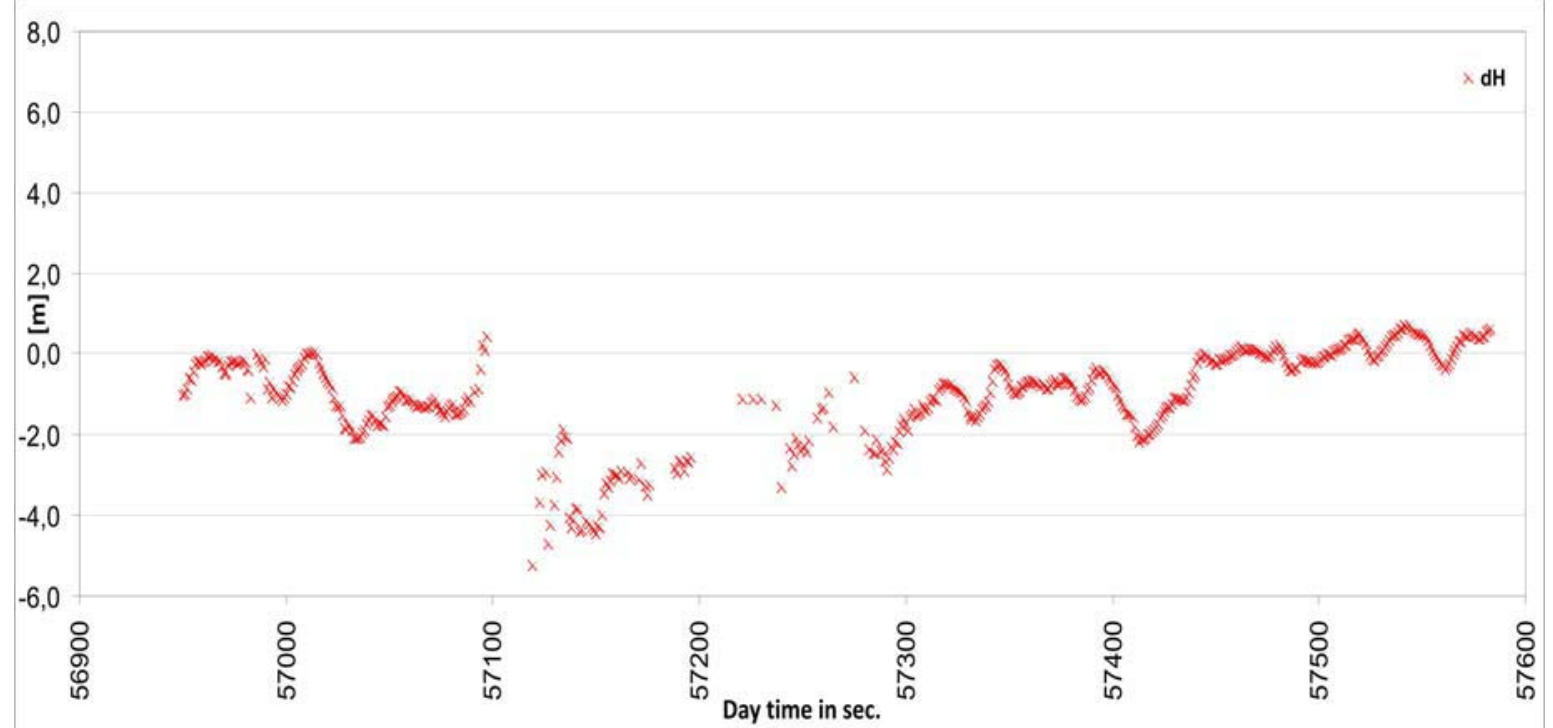

Fig. 8c. The differences of $\mathrm{H}$ coordinates computed for Septentrio receiver with EGNOS 
The results show that EGNOS correction could be insufficient for good position determination. As shown by the results the values of differences often exceed $1.5 \mathrm{~m}$ defined by ESA. Some cases result from visibility of satellites during the car drive. The horizontal obstacles situated near the road cut off low-elevation satellites. It should also be noted that those results were obtained for quiet ionospheric conditions. It is possible that during an ionospheric disturbance those differences from references coordinates would be greater.

\section{CONCLUSIONS}

The undertaken tests showed that for future measurement managed in the project it is important to select the road for measurements very carefully. It could be the short segments of the road but in the area of fully open horizon. The results depend on the satellite visibility (especially for observations with EGNOS corrections). The results showed that even during quiet geomagnetic conditions the obtained coordinates could exceed the level defined by ESA. They also give a chance for improvement of accuracy by using other corrections, which are planned to be computed in the next task of EEI project.

\section{ACKNOWLEDGMENTS}

The work has been supported by EGNOS-EUPOS Integration project PECS Agreement No. 98085.

\section{BIBLIOGRAPHY}

Antemijczuk O., B. Szady, K.A. Cyran, Integrity Events Analysis at OLEG GNSS Station in EGNOS Data Collection Network, Man-Machine Interactions 2 (T. Czachorski et al. Eds.),

Advances in Intelligent and Soft Computing 103, Springer, 95-103. 2011

Bosy J., Graszka W., Leończyk M. [2007] ASG-EUPOS. A Multifunctional Precise Satellite Positioning System in Poland, European Journal of Navigation, Vol. 5, Nr 4 (September 2007), pp. 2-6, Reed Business bv, 2007

EGNOS - A Cornerstone of Galileo - ESA Publication Division, (ESA SP-1303), 2006

EUPOS Technical Standards - Resolution of the International EUPOS ${ }^{\circ}$ Steering Committee13th Conference, Bucharest, Romania, 23 - 24 April 2008

Jaworski L., A. Swiatek, EGNOS - EUPOS Integration Project for the territory of Poland, (2009) Proceedings of 2ND GNSS VULNERABILITIES AND SOLUTIONS Conference, 2 - 5 September 2009, Baška, Croatia

Safety of Life Service Definition Document, (2011), European Commission DirectorateGeneral for Enterprise and Industry, s. 23-33

Received: 2012-11-21,

Reviewed: 2013-02-26, by K. Cyran,

Accepted: 2013-05-24. 